Review Article レビュー論文ーシリーズ 117

Invited Peer-Reviewed Article 招待査読論文

\title{
Understanding the Significance of Cultural Branding in Brand Theory
}

\section{ブランド研究における \\ カルチュラルブランディングの意義の理解}

\author{
Kayoko Honjo*1 \\ 東洋学園大学 \\ 本庄 加代子
}

${ }^{* 1}$ Toyogakuen University, kayoko.honjo@gmail.com

\begin{abstract}
This article examines the understanding and significance of cultural branding of Holt, which is evaluated as a bridge between CCT and brand strategies. This task is performed while focusing on problem consciousness, perspective to brands and academic area on which to rely. The model is positioned as the interpretivism which deals with transcendent concepts for culture and brand, and its construction process complements traditional positivism and can be considered to provide strategic flexibility and practicality. It is also showed strong brands are more likely to be criticized by communities, so brand is not of the absolute property, but rather the ideal state of the brand that meets the managerial goal, constrained by environment and having a dynamic property.
\end{abstract}

Keyword : Paradigms of brand theory, Interpretivism, Icon brand, CCT (Consumer Culture Theory)

要約 : 本稿は, 消費文化論とブランド研究の架け橋とされる Holt のカルチュラルブランディングについて, 問題意識, 依拠す る学問, ブランドの捉え方に注目し，ブランド研究に対する意義を考察する。同モデルは文化とブランドという超越的な概念と その形成の道筋を扱っている。これは，解釈主義に位置づけられるが，共約不可能とされる伝統的パラダイムを補完し，更に戦 略的柔軟性亡実践性を備えている。ここでは, ブランドは, 強くなればなるほど社会的批判を受けやすくなることが問題として 示されている。このことから, ブランドの理想形とは社会的問題の解決手段でもあり, 絶対的資質のものではなく, 経営目標と 合致する “状態”である可能性を示している。その動態性を前提とした理論の更なる洗練が必要であることが指摘できる。

キーワード : ブランド研究のパラダイム，解釈主義，イコンブランド，消費文化論（CCT）

Information : Received 2 December 2019; Accepted 19 December 2019

\section{I. 背景と目的}

2004 年 D. B. Holt が提唱したカルチュラルブランディ ングは“型破り”なアイデアだった。なぜなら，そこに はブランド研究の主流である心理学に基づく消費者行動 研究，そしてそれを基盤としたブランドマネジメントの アプローチとは一線を画したブランド観が提示されてい たからである。Holt が提示したのは，文化 ${ }^{1)} と$ 企業によ る商業的支配の対立構造を背景に，理想と現実に戸惑う 人々の不安や欲求が社会的イデオロギーと共振しながら, ブランドが文化と結びつくことで人々のアイデンティティ
の拠り所となるイコンブランドが構築されるというモデ ルである。

Holt は, これまでのブランド研究を問い直す挑戦的な 立場をとり続けている (Holt, 2004, 2017; Holt \& Cameron, 2010）。彼の所論は, 消費文化論（以降 CCT）の中に位 置づけられるが, 経験価值やブランドコミュニティに関 わる諸研究とも異なり, ポス卜構造主義を立脚点に文化 と歴史的連続性という超越的視点をブランド研究に持ち 込む。更に実践のための理論と社会的課題解決の意識を 強く持ち CCT を消費文化戦略（CCS）として発展させて いる (Holt, 2017)。

本稿では CCT とブランド研究との懸け橋と評価され 
る (Arnould \& Thompson, 2005) カルチュラルブランディ ングを関連する諸研究の系譜の中に読み解きブランド研 究における意味を見出す。

\section{II. 企業とブランドの関係性の摇らぎ}

社会学ではブランドなどに関わる現象を扱う際に，個 人の行為の総和ではなく，その影響関係から生まれる創 発特性に注目する（Durkheim, 1895/1978）。近年，会社 や家族といった準拠集団の崩壊によって社会の構造区分 が曖昧となるリキッド化がすすみ，個人のアイデンティ テイが摇らいでいる（Bauman, 2004/2007）。アイデン ティティと購買の関係については古くから指摘があるが (e.g., Belk, 1988） ポストモダンと呼ばれる生活者の移り 気で矛盾した消費行動は加速している。消費者は，時と 場合に応じたアイデンティティの切り替えにより，ブラ ンドから見出す意味を変容させていく。また SNS の台頭 によりブランドコミュニティ（Muniz \& O'guinn, 2001） などの消費者間の愛好集団が形成される一方で，企業支 配への嫌悪を示す動きが強まる（Holt, 2016; Thompson \& Arsel, 2004)。

Holt（2016）は，今後の企業の競合はサブカルチャー であるという。消費者は企業から一方的な情報よりもコ ミュニティの文脈に影響される。また特定のブランドが ひとつの文化として成功すればするほど，地域のコミュ ニティや慣習に影響を与え人々のイデオロギーを刺激し， 既存の文化との対立を引き起こす。成功するブランドの ジレンマである。例えばスターバックスは，その成功の 裏で地域の契茶店や茶文化を衰退へと追い込んでいる (Holt, 2002; Thompson \& Arsel, 2004)。また Thompson, Rindfleisch, and Arsel（2006）は文化の否定的な文脈の中 でユーザーの自己嫌悪につながるブランドを「ドッペル ゲンガーブランド」として表現している。

\section{III. ブランド研究と文化}

ブランド研究は大きく 2 つのパラダイムに分けられ
る。一つは個々の消費者の知識と情報処理に焦点をあて た伝統的な実証主義的アプローチと，ブランドを総体と してとらえ，文化を相互の要素・概念間の関係性の中で 捉えていく解釉主義である（Allen, Fournier, \& Miller, 2008）。後者のパラダイムによる研究は，前者の研究に 遅れて活発化した（Heding, Knudtzen, \& Bjerre, 2015）。

実証主義アプローチは，ブランド研究がマーケティン グ論の一大分野として確立されていく上で多大な貢献を 果たし，ブランドの役割を経営上欠かせぬものとした。 特にD. A. Aaker が 1991 年に発表した Managing Brand Equity はそれまでのブランドに関する実証主義の緒論を 整理・体系化した重要な功績である（Aaker, 1991/1994）。 ブランドは消費者の心の中に知識構造として存在してい るとされ（Keller, 1993）ブランドは購買のリスクをヘッ ジし，情報処理を簡略化させ，取引コストを下げていく などの機能をもつ（Maheswaran, Mackie, \& Chaiken, 1992）。ブランド価值の測定は, 消費者のブランド知識 を基準とし（Farquhar, Han, Herr, \& Ijiri, 1992; Keller, 1993）これをベースに無形資産として算定される。米国 で M \& A 市場が勃興する 1985 年前後からブランド価值 が注目されるようになり活発化した（Keller, 1998/2000）。 一方で文化的意味を扱う解釈主義アプローチに列なる 研究も古くから散見される。Gardner and Levy（1955） の物理的特徴以外の価值への注目や, Packard \& Payne （1957）やDichter（1960）による自動車の選択と購買者 の理想像との関係性への言及, また Belk（1988）の拡張 自己や Hirschman and Holbrook（1982）の経験価值など, 今日的な解釈主義研究の基礎は早くから提示されてい た。特にブランドとの関連性が色濃いのは言語学から派 生した記号論である。Lévi-Strauss（1958/1972）は「こ とば」と「もの」を一体のものとして扱い, 現象のダイ ナミズムを構造的に捉える。Barthes（1957/1967）は， 文化における神話（ことば）の作用を示した。Baudrillard （1970）は, 高度化社会におけるモノ消費の記号化を描 いた。マーケティング研究における Leymore（1975）に よる広告表現研究などにつながっていく。

このような広範囲にわたる研究潮流は, McCracken （1986）を基点に Arnould and Thompson（2005）によっ て CCT としてゆるやかに統合され, 文化の存在感が高 
Review Article レビュー論文ーシリーズ 117

まっていく。その中で Muniz and O'guinn（2001）や McAlexander, Schouten, and Koenig（2002）のブランドコ ミュニティ研究, そして Holt（2004）のカルチュラルブ ランディング研究が登場する（Arnould \& Thompson, 2005; Heding, Knudtzen, \& Bjerre, 2015)。

\section{Holt の問題意識とモデル}

Holt は集合としての消費者とマクロレベルでのブラン ドを取り巻く文化に強い問題意識をもち，消費を規定す る要因として文化的意味体系とそれを構築する歴史的連 続性に注目する（Holt, 2004）。また彼はポストモダンの 思想の中でも, ポスト構造主義のアプローチをとり, 社 会的集合体の象徵的表現，再生，潜在的意味変換を説明 してきた方法論（例 VALS や AIO モデルなど）を超え て，社会的消費パターンとして包括的にブランドをとら える超越的視角を導入する（Holt, 1997）。

彼が提唱するモデルは前述の「成功するブランドのジ レンマ」の緊張関係を援用するものである。それは社会 の矛盾から生じる人々の願望や不安, イデオロギーをも 摇るがす潜在的な意識に対して，ポピュリストの世界の 中でアイデンティティ神話 ${ }^{2) を}$ 語ることによって，その 象徴となるイコンブランドを人々に内在する不安や願望 の拠り所として機能させる方法である。Leymore（1975） は，広告を現代の我々の社会の秩序を構築するシステム の一つとなる隠された神話と捉え, 二項対立モデルによ り, 社会の中における対立や葛藤, 不安を解消する神話 の働きを分析した。Holt は神話構造をブランド戦略の解 釈へと援用する（Holt, 2004; Holt \& Cameron, 2010）。

Holt によるイコンブランドとは，ブランドの物語が文 化的な象徴として神格化され，人々のアイデンティティ にとって価值のあるものと見なされるようになっていく 中で，特定の価值観を熱く支持する人々の間で自己を表 現する共通の手段となりうるものである (Holt, 2004; Holt \& Cameron, 2010)。イコンブランドとその他のブランド との間には，明確な境界線があるわけではなく，アイデ ンティティの程度によって分類される。イコン化できる 対象には制約はなく，企業ブランドや事業ブランド，製
品ブランドといったカテゴリー分けや高関与や低関与と いった商品分野に限定されない。Holt はブランド構築に おける文化の視点は，いかなるカテゴリーでも欠くこと のできないと主張し，これまでの消費者行動アプローチ をマインドシェアモデルと呼び, 競争激化のレッドオー シャンに臨む戦略だと批判する（Holt, 2004, 2017; Holt \& Cameron, 2010)。

\section{V. 意義と考察}

このように 1985 年前後から注目されるブランド研究 は，その軸足が実証主義から解釈主義パラダイムへとシ フトしつつある（Heding, Knudtzen, \& Bjerre, 2015）。そ して研究の深化に伴いブランドの定義も多義的に広がる。 しかし経営上のブランドの課題は明確である。それは利 害関係者がブランドと呼ぶ対象がいかに広く愛好される ようになり，売れ続けるかであり，そのための仕組みを 作り，企業の永続性を保つことが基軸となる。

この実践的課題に応える上で, カルチュラルブランディ ングの視点は，ブランドが強化され社会的制約を受ける 中で, いかに社会と人々の葛藤の構造を捉え, その葛藤 に応えるためのブランドとして進化させるのかという方 法論である。これは, 顧客の認知を中心とする知識べー スのアプローチやまたブランド・エクイティやブランド リーダーシップ（Aaker \& Joachimsthaler, 2000/2000）で は補えない視点である。このような視座から考えれば, これまでの伝統的なブランド研究の蓄積と Holt のアプ ローチは，対立するものではなく戦略的補完関係にある 可能性が高い。むしろこれまでの研究体系の蓄積の上に Holt のアイデアが立脚しているとも考えられる。ただ し，両者は，ブランドの捉え方とその育成方法で大きな 差が生まれる。規定したブランド価值の維持強化を目指 しマーケティング戦略や組織との整合しながら展開する 伝統的な方法と, 外部の文化資源に織り込むようにアプ ローチする方法との違いや次元は異なり, マネジメント 上の整理は必要であろう。

その際，方法論としての手続きの問題もある。眓 1 に 示す通り解釈主義の難しさは, 多次元的デー夕によって 


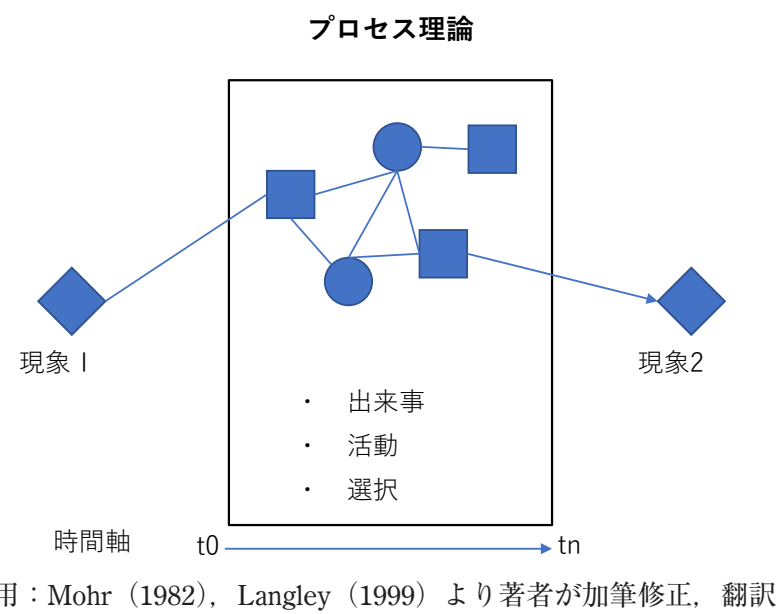

現実と現実の関係性を説明するプロセス理論としての特 徴にある（Mohr, 1982）。質的なプロセスデー夕を時間軸 で見せていくこのアプローチは，複雑な現象を複雑なま ま一体の構造としてとらえ, 現象の説明力を高めようと する。ここで重要となるのは“パターンの把握”である (Langley, 1999)。このアプローチは，データを最小単位 の変数まで分解し，環境を固定することで純化した状況 をつくる統計的手続きとは異なり，変数間の因果関係が 直接的には結びつかないこともある。これは CCT の短 所でもあり長所でもある。克服の手がかりの一つはアク ションリサーチ3)である。解釈主義は厚い記述を行うこ とが特徴であるため参与観察と親和性が高いが, アクショ ンリサーチは，研究者自ら関与し実行プロセスと戦略結 果の密接な影響関係を開示できる。ただし，このために は Holt (2017) が指摘するように, CCT は CCS (Consumer Cultural Strategy）として戦略的側面を強化することが求 められる。

最後に, このカルチュラルブランディングの意義を考 えるには，イコンブランドという馴染みのない概念が鍵 であろう。Holt（2004）はイコンブランド化への進化プ ロセスとして, マインドシェアブランドからアイデンティ ティブランド，イコンブランド化への連続性を示してい る。しかし既述したように，ブランドが成功すればする ほど，消費者や土着文化との対立構造は強まり，訴訟コ ストや CSR といった投資が必要になる。ブランドの目標
設定をする場合においては経営資源の限度を踏まえて弾 力的に調整する必要性があるため, イコンブランド化す ることが必ずしも合理的ではないといえるかもしれない。 企業は，強いブランドを構築するために経営されている わけではない。このことはイコンブランドに限らず，こ れまでブランド研究が暗に追い求めてきた「強いブラン ドを目指す」とは, 経営戦略上どういう状態であるのか を吟味する必要性を示唆している。恐らくそれは「強い ブランド」とは何かという問題提起では無く, 経営上, 必要とされるブランドはどういう“状態”なのか, とい う環境制約的なブランド論の起点となるものであろう。

以上のようにカルチュラルブランディングが提示する 枠組みは, ブランド研究に文化を組み込む土台を提供し， ブランドの社会的存在感が高まれば高まるほど，無視で きない文化という超越的な概念を, 具体的な戦略レベル に落とし込む重要性を提起する。そして伝統的パラダイ ムを補完する戦略的柔軟性を備える。更にブランドには 絶対的資質ではなく環境制約的な側面があり, 研究を進 化させるためには, ブランドの動態的変容を前提に, 実 践的視座にたった理論構築の洗練が必要であることも示 唆している。

注

1）文化の定義に唯一のものはなく Holt 自身も明確に文化の定 義を定めず論をすすめている。本稿では文化人類学者の Geerts（1973/1987）による，文化は人間の行動を支配する 
制御装置を参考に，共有された意味のパターン・体系・社 会的規範としている。

2）神話 myth はギリシア語のミュトス mythos に由来し，論理 的な思考, ないしその結果の言語的表現であるロゴス $\log 0$ に対し，事実そのものに関係しながらもその背後にあ る深い隠された意味を含む「神聖なる叙述」とされる（ブ リタニカ国際大百科事典 小項目事典“神話” http:// japan.eb.com/rg/article-05968200)

3） 1946 年にLewin が提唱した研究法。経営学に援用され洗練 化が図られている（e.g., Dickens \& Watkins, 1999）。

\section{References}

Aaker, D. A. (1991). Managing brand equity: Capitalizing on the value of a brand name. New York: Free Press.（陶山計介 - 中 田善啓・尾崎久仁博・小林哲（訳）（1994）。『ブランド・エ クイテイ戦略：競争優位をつくりだす名前, シンボル， ス ローガン』ダイヤモンド社)

Aaker, D. A., \& Joachimsthaler, E. (2000). Brand leadership. New York: Simon and Schuster. (阿久津聡（訳）（2000）。『ブラン ド・リーダーシップ』ダイヤモンド社)

Allen, C. T., Fournier, S., \& Miller, F. (2008). Brands and their meaning makers. Handbook of consumer psychology, 781-822.

Arnould, E. J., Press, M., Salminen, E., \& Tillotson, J. S. (2019). Consumer culture theory: Development, critique, application and prospects. Foundations and Trends in Marketing, 12(2), $80-166$.

Arnould, E. J., \& Thompson, C. J. (2005). Consumer culture theory (CCT): Twenty years of research. Journal of Consumer Research, 31(4), 868-882.

Barthes, R. (1957). Mythologies. New York: Hill and Wang.（篠沢秀 夫（訳）。（1967）。『神話作用』現代思潮新社）

Baudrillard, J. (1970). La société de consommation: Ses mythes, ses structures. Paris: Gallimard. (今村仁司・塚原史（訳）（1979）. 『消費社会の神話と構造』紀伊國屋書店)

Bauman, Z. (2004). Identity: Conversation with Benedetto Vecchi. Cambridge: Polity Press.（伊藤茂（訳）（2007）、『アイデン テイテイ』日本経済評論社)

Belk, R. W. (1988). Possessions and the extended self. Journal of Consumer Research, 15(2), 139-168.

Dichter, E. (1960). The strategy of desire. New Jersey: Transaction Publishers.

Dickens, L., \& Watkins, K. (1999). Action research: Rethinking Lewin. Management Learning, 30(2), 127-140.

Durkheim, E. (1895). Les regles de la methode sociologique. Paris: Presses Universitaires de France.（宮島喬（訳）（1978）。『社 会学的方法の規準』岩波書店）

Farquhar, P. H., Han, J. Y., Herr, P. M., \& Ijiri, Y. (1992). Strategies for leveraging master brands. Marketing Research, 4(3), 32-43.

Gardner, B. B., \& Levy, S. J. (1955). The product and the brand. Harvard Business Review, March-April, 33-39.

Geertz, C. (1973). The interpretation of cultures (Vol. 5019). New York: Basic books.（吉田禎吾 - 中牧弘允・柳川啓一・板橋 作美（訳）（1987）。『文化の解釈学 I』pp. 147-148，岩波現 代選書)
Heding, T., Knudtzen, C. F., \& Bjerre, M. (2015). Brand management: Research, theory and practice. London: Routledge.

Hirschman, E. C., \& Holbrook, M. B. (1982). Hedonic consumption: Emerging concepts, methods and propositions. Journal of Marketing, 46(3), 92-101.

Holt, D. B. (1997). Poststructuralist lifestyle analysis: Conceptualizing the social patterning of consumption in postmodernity. Journal of Consumer Research, 23(4), 326-350.

Holt, D. B. (1998). Does cultural capital structure American consumption? Journal of Consumer Research, 25(1), 1-25.

Holt, D. B. (2002). Why do brands cause trouble? A dialectical theory of consumer culture and branding. Journal of Consumer Research, 29(June), 70-90.

Holt, D. B. (2004). How brands become icons: The principles of cultural branding. Cambridge, MA: Harvard Business School Press.

Holt, D. B. (2016). Branding in the age of social media. Harvard Business Review, 94(3), 13.

Holt, D. B. (2017). Consumer culture strategy. In J. F. Sherry, \& E. M. Fischer (Eds.). Contemporary consumer culture theory (pp. 215-225). Oxford: Taylor \& Francis.

Holt, D. B., \& Cameron, D. (2010). Cultural strategy: Using innovative ideologies to build breakthrough brands. Oxford: Oxford University Press.

Keller, K. L. (1993). Conceptualizing, measuring, managing customerbased brand equity. Journal of Marketing, 57(1), 1-22.

Keller, K. L. (1998). Strategic brand management: Building, measuring, and managing brand equity. New Jersey: Prentice Hall. (恩蔵直 人・亀井昭宏（訳）（2000）。『戦略的ブランドマネジメント』 東急エージェンシー出版部)

Langley, A. (1999). Strategies for theorizing from process data. Academy of Management Review, 24(4), 691-710.

Lewin, K. (1946). Action research and minority problems. In G. W. Lewin (Ed.). Resolving social conflicts. New York: Harper \& Row.

Lévi-Strauss, C. (1958). Anthropologie structural. Paris: Plon. (荒川 幾男・生松敬三・川田順造・佐々木明・田島節夫（訳） (1972)。『構造人類学』みすず書房)

Leymore, L. V. (1975). Hidden myth: Structure and symbolism in advertising. London: Heinnemann.

Maheswaran, D., Mackie, D. M., \& Chaiken, S. (1992). Brand name as a heristic cue: The effects of task importance and expectancy confirmation on consumer judgment. Journal of Consumer Psychology, 1(4), 317-336.

McAlexander, J. H., Schouten, J. W., \& Koenig, H. F. (2002). Building brand community. Journal of Marketing, 66(1), 38-54.

McCracken, G. (1986). Culture and consumption: A theoretical account of the structure and movement of the cultural meaning of consumer goods. Journal of Consumer Research, 13 (June).

Mohr, L. B. (1982). Explaining organizational behavior. San Francisco: Jossey-Bass.

Muniz, A. M., \& O'guinn, T. C. (2001). Brand community. Journal of Consumer Research, 27(4), 412-432. 
Packard, V., \& Payne, R. (1957). The hidden persuaders. New York: D. McKay Company.

Sherry Jr, J. F. (2001). Postmodern marketing: A primer for managers. Harvard Business Review, June, 98-105.

Thompson, C. J., \& Arsel, Z. (2004). The Starbucks brandscape and consumers' (anticorporate) experiences of glocalization. Journal of Consumer Research, 31(3), 631-642.

Thompson, C. J., Rindfleisch, A., \& Arsel, Z. (2006). Emotional branding and the strategic value of the Doppelgänger brand image. Journal of Marketing, 70(January), 50-64.

\section{本庄 加代子（ほんじょう かよこ）}

東洋学園大学 准教授/神戸大学大学院 経営学研究科 博士後期課程 / (株) 博報堂コンサルティング マネジャー を経て現職。 